\title{
Effect of Cryogenic treatment on Wear Properties of Aluminum Al356 - Zirconium Silicate Particulate Metal Matrix Composite
}

\author{
Shivanna, Sameer S Kulkarni, Samarth C, Sagar R, Sanil K R.
}

\begin{abstract}
Metal matrix composite (MMC's) are very much familiar in the field like automobile and aerospace industries owing to their excellent wear and mechanical properties. The fundamental aim of this paper is to augment cognizance amongst the researchers and to attract their consideration towards the present approach to treat with the cryogenic usage for the nonferrous metals. In this writing it is endeavor to deliver the examination findings of character of cryogenic usage on Wear Properties of Al356-ZrSiO ${ }_{4}$ Particulate Reinforced metal matrix Composites adapted by Stir Casting technique. The amount of reinforcement is changed from 0 to $12 w t \%$ in track of $3 \%$. The ready composites are exposed to wear testing as per ASTM standards using pin on disc machine. The hardness of the composites was found to augment with augment in reinforcement in the composite. The inference obtained discloses that as reinforcement content in the composites increment and execution of cryogenic usage to composite amended the wear resistance.
\end{abstract}

\section{INTRODUCTION}

In engineering purpose, enormous interest is to examine for modern materials display higher wear and mechanical properties. A composite material is basically a kind of structural material produced by blending two or more distinct materials, are unachievable by individual materials alone. The constituents individually do not serve the required function by themselves but they did it when they were put together [1]. Particle reinforced aluminum metal matrix composites have improved in the last few years, in direction to diminish the weight of components in constructional applications and to reform their mechanical properties and wear properties. Metal matrix composites are a class of material with the capability to merge the properties of pottery (high strength and high modulus) with those of metals or alloys (ductility and toughness) to exhibit momentous improvements in the mechanical production of the composites over those of the of the monolithic metals or alloys. During the spent two decades,

Manuscript received on January 27, 2021.

Revised Manuscript received on February 22, 2021.

Manuscript published on February 28, 2021

* Correspondence Author

Shivanna *, Department of Mechanical Engineering, Don Bosco Institute of Technology, Bangalore, Karnataka, India. Email:shivannamechdbit@gmail.com

Sameer S Kulkarni, Department of Mechanical Engineering, Don Bosco Institute of Technology, Bangalore, Karnataka, India

Samarth C, Department of Mechanical Engineering, Don Bosco Institute of Technology, Bangalore, Karnataka, India

Sagar R, Department of Mechanical Engineering, Don Bosco Institute of Technology, Bangalore, Karnataka, India

Sanil K R., Department of Mechanical Engineering, Don Bosco Institute of Technology, Bangalore, Karnataka, India
Keywords: Al35, $\mathrm{ZrSiO}_{4}$, Cryogenic, Wear, Hardness, materials, where the properties obtained by mixing of these

a lot of examination has been accursed to restraint the dimension, shape, morphology, and arrangement of the grains in pottery, in direction to reform the mechanical and wear properties. Metal-matrix composites have been came forth as possible alternatives to accepted alloys in high-strength and stiffness applications. Cost is the key substitute for their more extensive recourse in modern industry, although possible benefits in weight rescuing, and increment component life.

In recent years, ceramics have widely been considered as reinforcement materials to improve properties of metal matrix composite materials. To further increase the properties of composites cryogenic treatment is done. The exposed of the material to highest cold hardness, fortify and molecular alignment in the micro level is refined and the material has longer life. The researchers disclose the useful result of cryogenic usage on nonferrous metal aluminum [2]. It was reported in the examination of the wear conduct of Al6061-SiC particulate reinforced composites prepared by liquid metallurgical technique. that scattered $\mathrm{SiC}$ in Al6061 alloy and $\mathrm{Al}_{2} \mathrm{O}_{3}$ in $\mathrm{Al} 7075$ alloy with the increased \% of reinforcements in respective alloy material concluded that augment in hardness ,tensile strength and improvement in density of composites [3]. It was clearly demonstrated that the result of applied load and temperature on the dry sliding wear conduct of Al6061 alloy matrix composites strengthen with $\mathrm{SiC}$ whiskers or $\mathrm{SiC}$ particulates and comprehend that, the wear rate reduced as the applied load is increased. In the examination on the wear conduct on Al6061 strengthen with $\mathrm{Al}_{2} \mathrm{O}_{3}$ particle [3]. When a enough high load is attach on the terminal, the matrix phase is plastically malformed, and the strain is partly carry over to the particulates, which are brittle with diminutive failure strains. It impart from the literature that very slight message are present concerning the result of Deep Cryogenic treatment(DCT) on Wear Characterization of the composites with metal matrix composites of Al356 alloy reinforced with $\mathrm{ZrSiO}_{4}$ particulates. Thus in this trial work Cryogenic usage was devote to $\mathrm{Al} 356$ - $\mathrm{ZrSiO}_{4}$ particulate reinforced metal matrix composites to study its influence on Wear Properties of $\mathrm{Al} 356-\mathrm{ZrSiO}_{4}$ particulate reinforced metal matrix composites.

\section{EXPERIMENTAL PROCEDURE}

\section{A. Materials used}

The matrix material used for the present contemplation is Al356 .Table. 1 fetters the chemical constitution of A1356.The reinforcing material chosen was $\mathrm{ZrSiO}_{4}$ of particle size $44 \mu \mathrm{m}$.

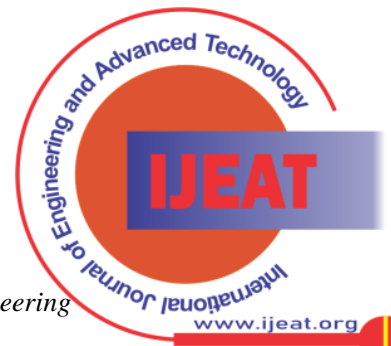


Effect of Cryogenic treatment on Wear Properties of Aluminum A1356 - Zirconium Silicate Particulate Metal Matrix Composite

Table. 1. Chemical constitution of Al356

\begin{tabular}{|l|l|l|l|l|l|}
\hline Alloy & $\mathrm{Si}$ & $\mathrm{Fe}$ & $\mathrm{Cu}$ & $\mathrm{Mn}$ & $\mathrm{Mg}$ \\
\hline Al356 & 7.5 & 0.2 & 0.25 & 0.35 & 0.45 \\
\hline $\mathrm{Ni}$ & $\mathrm{Zn}$ & $\mathrm{Ti}$ & $\mathrm{Pb}$ & $\mathrm{Al}$ \\
\hline 0.1 & 0.35 & 0.2 & 0.1 & remainder \\
\hline
\end{tabular}

B. Properties of $\mathrm{ZrSiO} 4$

- $\mathrm{ZrSiO}_{4}$ has high hardness

- Modulus of elasticity is high

- Very good thermal stability

\section{Preparation of Composites}

The liquid metallurgy course has been adopted to manufacture the cast composites as express below. Preheated $\mathrm{ZrSiO}_{4}$ flour of particle dimension $44 \mu \mathrm{m}$ was introduced into the whirlpool of the molten alloy of Al356 after active degassing mechanical awakening of the molten alloy for Time of $10 \mathrm{~min}$ was realize by using ceramic coated steel impeller. A speed of $400 \mathrm{rpm}$ was maintained. A pouring temperature of $730{ }^{\circ} \mathrm{C}$ was adopted and the molten composite was poured into pre heated cast iron moulds. The degree of combination of $\mathrm{ZrSiO} 4$ in the matrix alloy was changed from 0 to $12 \%$ in steps of 3 . Thus composites were procured in the form of cylinders of diameters $22 \mathrm{~mm}$ and length $210 \mathrm{~mm}$.

\section{Cryogenic Treatment}

Cryogenic treatment adverts to prone material to very low temperature. This procedure is not restricted in application to metals, but can also be applied to broad range of materials. Several distinct cryogenic processes have been tested by researchers. These implicate a association of deep freezing and tempering cycles. Generally, they can be depict as a restraint gloomy of temperature from space temperature to $-193^{\circ} \mathrm{c}$, maintenance of the temperature for about 24 hours succeed by a restraint ascending of temperature back to the room temperature. This treatment influences the material in two ways. Firstly, it deduces retained austenite, and hence augment the hardness of the material. Secondly this treatment originate nucleation site for precipitation of abundant number of very fine carbide particles and microstructure changes [4].

\section{SPECIMEN PREPARATION \&TESTING}

Specimens were prepared as per ASTM standards for the measurement of hardness as well as for wear behavior from cast composites.

\section{A. Cryogenic Process}

The Al356-Zirconium Silicate Particulate Reinforced Composite samples were disclosed to cryogenic treatment with the following arguments. Cooling time: 6 hours at the rate of $2^{\circ} \mathrm{C} / \mathrm{min}$, Soaking time: 24 hours at $-193^{\circ} \mathrm{C}$, Medium used: Liquid Nitrogen, Warming time: 6 hours at the rate of $2^{\circ} \mathrm{C} / \mathrm{min}$.

value compared betr
MMCs with DCT.

\begin{tabular}{|c|lc|c|}
\hline SL NO & \multicolumn{2}{|l|}{ Composition } & Hardness (BHN) \\
\hline 1 & \multicolumn{2}{|l|}{ Al356+0\% $\mathrm{ZrSiO}_{4}$} & 62.16 \\
& Al356+0\% $\mathrm{ZrSiO}_{4}$ & 63.20 \\
& DCT & \\
\hline 2 & Al356+3\% $\mathrm{ZrSiO}_{4}$ & 64.26 \\
& Al356+3\% $\mathrm{ZrSiO}_{4}$ & 66.86 \\
& DCT & \\
\hline 3 & Al356+6\% $\mathrm{ZrSiO}_{4}$ & \\
& Al356+6\% $\quad \mathrm{ZrSiO}_{4}$ & 64.28 \\
& DCT $\quad$ & 65.86 \\
\hline
\end{tabular}

\section{B. Pin on Disc tester}

A pin on disc tester was used to extent wear, frictional force, and temperature. Tests were impel in agreement with

\begin{tabular}{|l|l|}
\hline Track Radius & $50 \mathrm{~mm}$ \\
\hline Sliding distance & $0.5-2.0 \mathrm{Km}$ \\
\hline Load & $10-40 \mathrm{~N}$ \\
\hline Speed & $400 \mathrm{RPM}$ \\
\hline
\end{tabular}

\section{. Hardness test}

Cryogenic treated and untreated composites.

\section{Microstructure}

The microstructure of Al356-zirconium silicate particulate metal matrix Composites specimen was investigate under metallurgical microscope.

\section{RESULTS AND DISCUSSION}

\section{A. Hardness testing}

The deviates in the hardness of composites with raised content of reinforcement shown in Fig.2 describe the change in hardness. It is detected that the hardness of $\mathrm{Al} 356-\mathrm{ZrSiO} 4$ composites enhance with raised capacity of the aluminium silicate reinforcement and cryogenic treatment. Finer the size enhanced is the hardness of composites and to lowering of wear rates [5]. This augment in are of the composite may be attributed due to the argument that the hard ceramic particles play as obstruction to he advancement of the dislocation with the matrix and good Further, the grow in hardness is due to the cryogenic treatment which backup for the molecular alignment in the microstructure.

Table4: Hardness value compared between MMCs \& 


\begin{tabular}{|c|c|c|}
\hline 4 & $\begin{array}{l}\mathrm{Al} 356+9 \% \mathrm{ZrSiO}_{4} \\
\mathrm{Al} 356+9 \% \quad \mathrm{ZrSiO}_{4} \\
\text { DCT }\end{array}$ & $\begin{array}{l}65.45 \\
69.08\end{array}$ \\
\hline 5 & $\begin{array}{l}\text { Al356+12\% } \mathrm{ZrSiO}_{4} \\
\mathrm{Al} 356+12 \% \\
\text { DCT }\end{array}$ & $\begin{array}{l}68.00 \\
70.90\end{array}$ \\
\hline
\end{tabular}

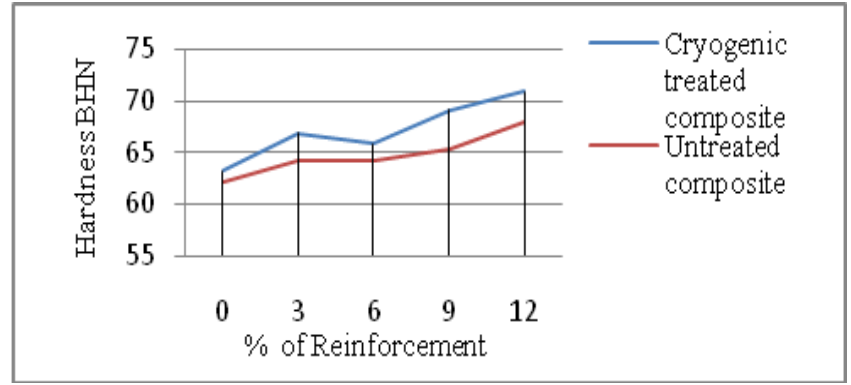

Fig. 2. Graph of Hardness compared between MMCs \& MMCs with DCT

\section{B. Wear testing}

The change in wear rate with sliding distance of the composite has been designed at four different loads which are shown in fig3a-h, It is observed that wear rate of composites and Cryogenic treated composites augment with augment in applied load. Also, with the augmentation of reinforced particles and advance sliding distance the wear rate diminish. Improved hardness results in diminish in wear rate. The elevated rise in initial stage gives rise to better wear corresponding to the run-in -wear. In case of cryogenic treated composite the wear resistance further augment due to molecular alignment.

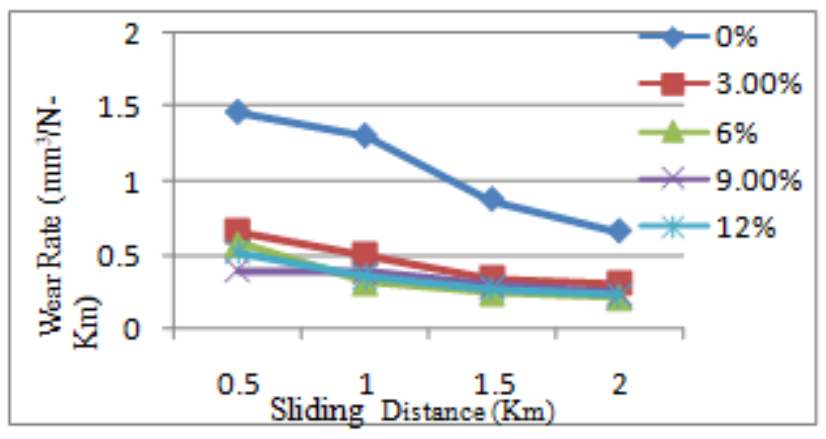

a)

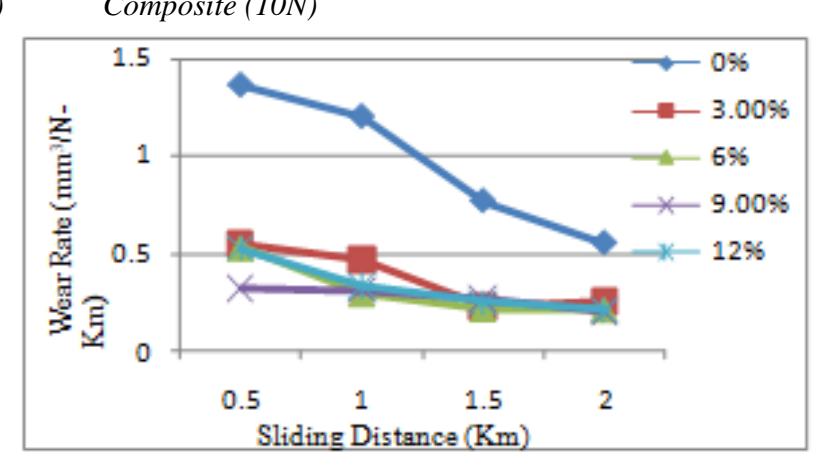

b) DCT Composite (10N)

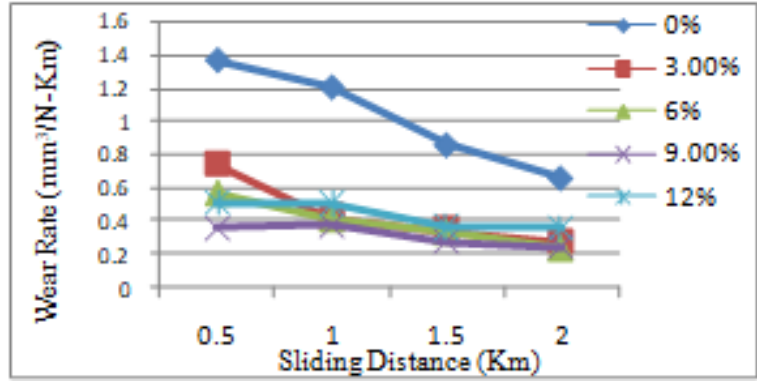

c) Composite $(20 \mathrm{~N})$

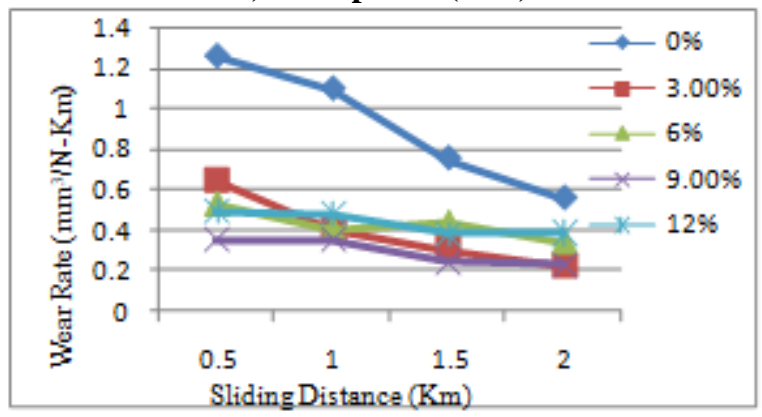

d) DCT Composite (20N)

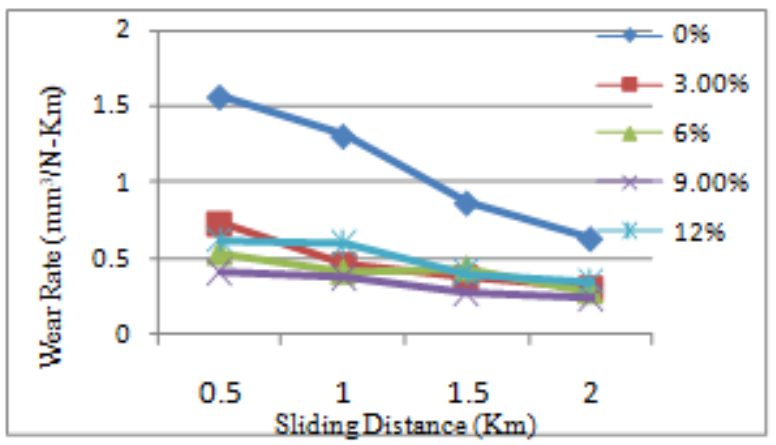

e) Composite $(30 \mathrm{~N})$

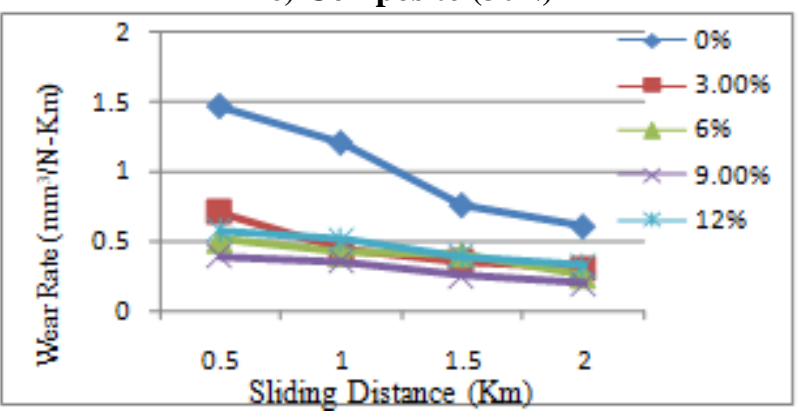

f) DCT Composite (30N)

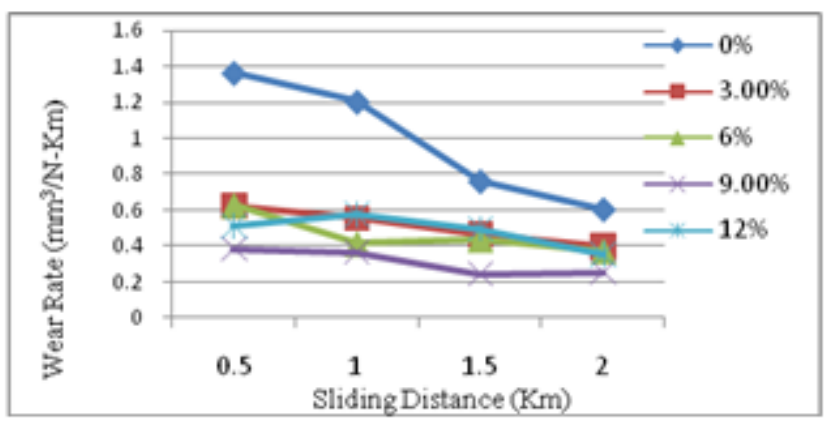

g) Composite (40N)

Published By:

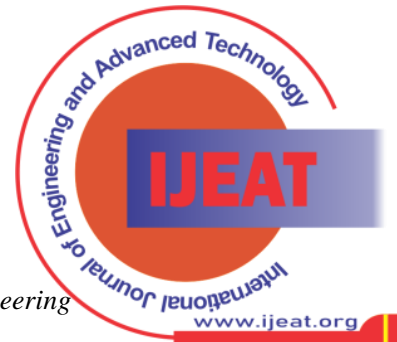
Exploring Innovation 


\section{Metal Matrix Composite}

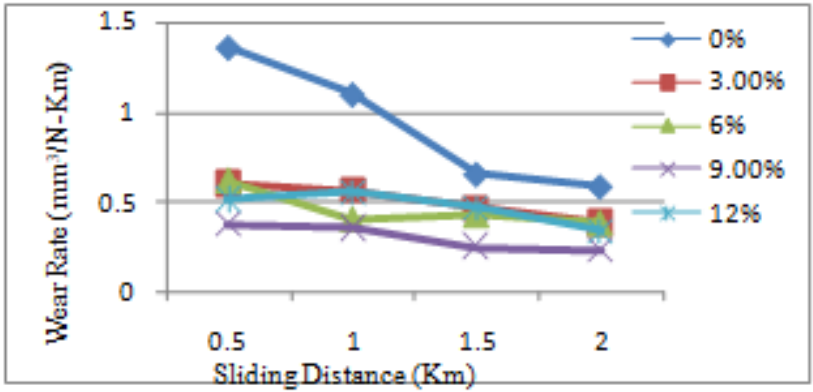

h) DCT Composite (40N)

Fig3a-h: The Comparison of wear rate of Composites and Deep Cryogenic treated (DCT) Composites against sliding distance at various loads.

\section{Microstructure}

Photomicrographs of $\mathrm{Al} 356+\mathrm{ZrSiO} 4$ composites are shown in Fig4.The conclusion of photomicrographs depict that the reinforcement particles diversified homogeneously in the matrix alloy. In augmentation to reinforcement particles the impingement of cryogenic processing has significant changes in the microstructure of MMCs and led to the transformation of $\alpha$ aluminium to $\beta$ phase[3], which has main strengthening performance on $\mathrm{Al} 356$ base alloy.

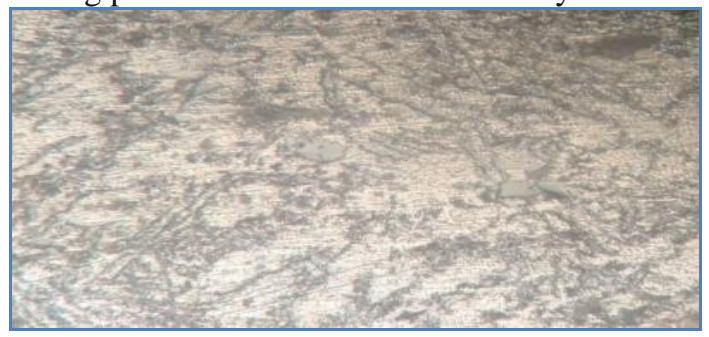

$500 \times(a)$
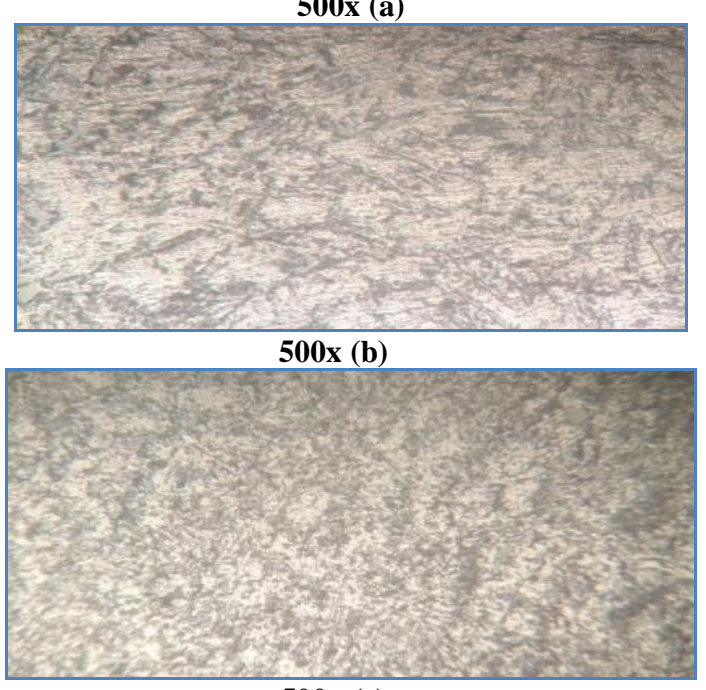

500x (c)

Fig 4: photomicrographs of

a) $\mathrm{Al356}$ Base alloy b ) $\mathrm{Al356}+12 \% \mathrm{ZrSiO}_{4}$ Composite c) Cryogenic treated $\mathrm{Al356}+12 \% \mathrm{ZrSiO}_{4}$ Composite.

\section{CONCLUSION}

The composite material with Aluminum as base alloy $\mathrm{Al} 356$ and $\mathrm{ZrSiO}_{4}$ particulates as reinforcement material were satisfactorily fabricated through liquid metallurgy route for $3 \%, 6 \%, 9 \%$ and $12 \%$ reinforcement. Wear rate diminish as sliding distance and load augment. The hardness of the composite found to be higher than the base matrix this is chiefly due to the reputation of hardened character of $\mathrm{ZrSiO}_{4}$ and deviate in the morphology of precipitates. Thus sum up the consistent arrangement of particle and cryogenic treatment assist for the improved wear rate and hardness of MMCs material.

\section{REFERENCES}

1. T.N.Baker, A.B.Gurcan "Wear behavior of AA6061 aluminum alloy and its Composites", Wear 188, pp185-191.1995.

2. A.Jeyachandran, V.S.K.Venkatachalapathy, K.Velmurugan \&

3. K.Thamizhmran "Effect of cryogenic treatment on microstructure and tribological properties ofA16061 Hybrid Metal Matrix Composite'IJERT,Vol7,2018, pp272-276.

4. Suresh.R, M.Prasanna kumar "Investigation of Tribological Behavior and its Relation with Processing and Microstructures of Al6061 Metal Matrix Composites” IJRET,Vol. 1, Issue 2, pp.91- 104.2013.

5. V. Leskovsek, M. Kalin, J.Vizintin, "Influence of deep cryogenic treatment on wear resistance of vacuum heat treated HSS," vacuum 80 (2003) 507-518.

6. S. Gopalakrishan, N. Murughan "Production and Wear Characterization AA 6061Matrix Titanium Carbide Particle Reinforced Composite by Enhanced Stir Casting Method", Composites: Part -B43, pp.302-308, 2012.

\section{AUTHORS PROFILE}

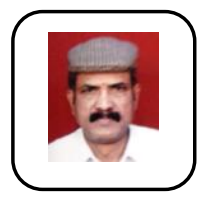

Dr Shivanna received B.E (MECH) from Bangalore University, PG from VTU \& PhD from VTU, Belaghavi $\mathrm{He}$ is working as HOD, Department of Mechanical Engineering, DBIT. He has 32 years of experience in Teaching \& Research. Publications: He has Published 15 research papers in repeated national \& international conferences \& journals, His research interests are cutting tools \& metal matrix composites. Membership: Life member of MISAMP, MISTE.

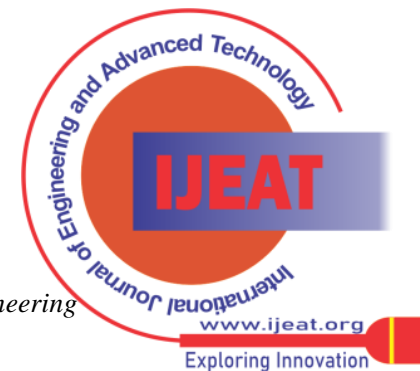

